OPEN ACCESS

Edited by:

Sufang Qiu,

Fujian Provincial Cancer Hospital,

China

Reviewed by:

Kubra Aral,

inönü University,

Turkey

Shaoming $\mathrm{Li}$

Affiliated Hospital of Qingdao

University, China

*Correspondence:

Boyu Tang

boyutang@126.com

${ }^{t}$ These authors have contributed equally to this work

Specialty section:

This article was submitted to

Cancer Immunity

and Immunotherapy,

a section of the journal

Frontiers in Oncology

Received: 09 June 2021 Accepted: 09 August 2021

Published: 30 September 2021

Citation:

Yao $Y$, Shen $X$, Zhou $M$ and Tang $B$ (2021) Periodontal Pathogens

Promote Oral Squamous Cell Carcinoma by Regulating ATR and NLRP3 Inflammasome.

Front. Oncol. 11:722797. doi: 10.3389/fonc.2021.722797

\section{Periodontal Pathogens Promote Oral Squamous Cell Carcinoma by Regulating ATR and NLRP3 Inflammasome}

\author{
Yufei Yao ${ }^{1+}$, Xin Shen ${ }^{1 \dagger}$, Maolin Zhou ${ }^{1}$ and Boyu Tang ${ }^{1,2 *}$ \\ 1 State Key Laboratory of Oral Diseases, National Clinical Research Center for Oral Diseases, West China Hospital of \\ Stomatology, Sichuan University, Chengdu, China, ${ }^{2}$ Department of Cariology and Endodontics, West China Hospital of \\ Stomatology, Sichuan University, Chengdu, China
}

Periodontitis is closely related to oral cancer, but the molecular mechanism of periodontal pathogens involved in the occurrence and development of oral cancer is still inconclusive. Here, we demonstrate that, in vitro, the cell proliferation ability and S phase cells of the periodontitis group (colonized by Porphyromonas gingivalis and Fusobacterium nucleatum, $\mathrm{P}+$ ) significantly increased, but the $\mathrm{G} 1$ cells were obviously reduced. The animal models with an in situ oral squamous cell carcinoma (OSCC) and periodontitisassociated bacteria treatment were constructed, and micro-CT showed that the alveolar bone resorption of mice in the $\mathrm{P}+$ group $(75.3 \pm 4.0 \mu \mathrm{m})$ increased by about $53 \%$ compared with that in the control group $(48.8 \pm 1.3 \mu \mathrm{m})$. The tumor mass and tumor growth rate in the $\mathrm{P}+$ group were all higher than those in the blank control group. Hematoxylin-eosin (H\&E) staining of isolated tumor tissues showed that large-scale flaky necrosis was found in the tumor tissue of the $\mathrm{P}+$ group, with lots of damaged vascular profile and cell debris. Immunohistochemistry $(\mathrm{IHC})$ of isolated tumor tissues showed that the expression of Ki67 and the positive rate of cyclin D1 were significantly higher in tumor tissues of the P+ group. The qRT-PCR results of the expression of inflammatory cytokines in oral cancer showed that periodontitis-associated bacteria significantly upregulated interleukin (IL)-6, tumor necrosis factor (TNF)- $\alpha$, IL-18, apoptosis-associated speck-like protein containing a CARD (ASC) (up to six times), and caspase-1 (up to four times), but it downregulated nuclear factor (NF)- $\kappa B$, NOD-, LRR- and pyrin domain-containing protein 3 (NLRP3), and IL-1 $\beta$ (less than 0.5 times). In addition, the volume of spleen tissue and the number of CD4+ T cells, CD8+ T cells, and CD206+ macrophages in the P+ group increased significantly. $\mathrm{HC}$ and Western blotting in tumor tissues showed that expression levels of $\gamma$-H2AX, p-ATR, RPA32, CHK1, and RAD51 were upregulated, and the phosphorylation level of $\mathrm{CHK} 1$ ( $\mathrm{p}$-chk1) was downregulated. Together, we identify that the periodontitis-related bacteria could promote tumor growth and proliferation, initiate the overexpressed NLRP3, and activate upstream signal molecules of ATR-CHK1. It is expected to develop a new molecular mechanism between periodontitis-related bacteria and OSCC.

Keywords: OSCC, NLRP3 inflammasome, ATR-Chk1, P. gingivalis, F. nucleatum 


\section{INTRODUCTION}

Oral cancer is the sixth most prevalent malignancy in the world, and oral squamous cell carcinoma (OSCC) accounts for approximately $90 \%$ of all oral malignancies, leading to significant morbidity and mortality (1). Carcinogenesis of OSCC is an intricate multistep process initiated by varied pathogenic factors, including genetic predisposition, bad habits, viral infections, and so on. While the possible molecular mechanisms in OSCC are being determined, the definitive reason for the initiation and development of OSCC is still unclear (2).

With the establishment and development of the field of "metagenomics," more and more in-depth research results suggest that the occurrence and development of OSCC were closely related to the oral symbiotic microbiome that occupied $90 \%$ of the human cell composition and exceeded the genetic information of the human genome 100 times. Periodontitis, a dental plaque-induced inflammatory disease, led to irreversible loss of attached tissues and alveolar bone and increases the risk of developing inflammatory tumors (3-6). Evidence has accrued that there might be a close relationship between suspected periodontal pathogen infection, periodontitis, and OSCC. The analysis of large clinical samples showed that the risk of oral cancer and gastrointestinal cancer was significantly increased in periodontal patients $(5,6)$. Clinically, the presentation of periodontitis was similar to some oral cancers, such as gingival cancer. In some cases, periodontal disease and gingival cancer occurred simultaneously at the same site. Moreover, a metaanalysis showed that the severity of periodontitis was significantly correlated with precancerous lesions and oral cancer (6). The results of metagenomics also showed that there are significant differences in bacterial composition between OSCC and non-tumor tissues. The difference of microbial communities between superficial and deep cancer tissue sites was mainly due to the different glycometabolism and acid tolerance to adapt to the different microenvironments $(3,7)$. The research now believed that the poor microenvironment of periodontitis was mainly triggered by Porphyromonas gingivalis. In the process of reshaping a disease-causing microbiome, P. gingivalis was believed to play a key role in the breakdown of homeostasis $(4,8)$. In addition, Fusobacterium nucleatum, one of the periodontal pathogens, promoted the proliferation ability of Tca8113 by causing DNA damage via the Ku70/p53 pathway, thereby promoting OSCC (9).

However, the functional manifestation of its core microbial community and its influence mechanism on the occurrence and development of tumors were still unclear. As we all know, inflammation and persistent infection might contribute to various human malignancies and the inflammasome-mediated immune mechanisms, and the monitoring mechanisms based on DNA damage responses (DDRs) played an important role in the progression of inflammatory tumors (10), failure of which led to accumulation of DNA damage and genomic instability. And mounting evidence has suggested that bacterial infections can elicit DNA damage in host cells. In order to ensure the integrity of the genome after cell injury, the cell usually activated a checkpoint mechanism to prevent the progression of the cell cycle. This response depended on two main phosphatidylinositol-3 kinase (PI3K)-related kinases, namely, ataxia telangiectasia-mutated (ATM) and ATM and Rad-3-related (ATR). The ATM-CHK2 pathway played an important role in the G1, S, and G2 phases and is extremely fast and sensitive to DNA double-strand breaks (DSBs), recruiting chromatin binding proteins such as $\mathrm{H} 2 \mathrm{AX}, \mathrm{MDC}$, BRCA1, RNF8, and 53BP1 to the double-strand break point rapidly. While the ATR-CHK1 pathway specifically acted on the S/G2 phase and mainly mediated the replication stress. TopBP1 and Rad9-Hus1-Rad1 were the key protein factors for the activation of the ATR-CHK1 pathway. TopBP1 could activate ATR kinase through binding to the ATR activation domain, triggering phosphorylation of downstream molecules including CHK1. $\mathrm{H} 2 \mathrm{AX}$ is a variant of the H2A protein family, which can be phosphorylated by kinases such as ATM and ATR in the PI3K pathway, forming $\gamma$-H2AX that can be used as a biomarker for DDR $(6,11)$.

Inflammasomes are a group of cytosolic protein complexes that are formed to mediate host immune responses to microbial infection and cellular damage. Assembly of an inflammasome triggers proteolytic cleavage of dormant procaspase- 1 into active caspase-1, which converts the cytokine precursors pro-interleukin (IL)- $1 \beta$ and pro-IL- 18 into mature and biologically active IL- $1 \beta$ and IL-18, and also induces pyroptosis, respectively (12). The NOD-, LRR- and pyrin domain-containing protein 3 (NLRP3) inflammasome has been under intensive investigation given its possible involvement in several human diseases, including immune inflammatory diseases and tumors. Now, data have suggested that there is a close relationship between NLRP3 inflammasome polymorphisms and different malignancies such as colon cancer and melanoma (13). In addition, during the infection process, microorganisms can utilize or hijack the biological functions of the infected cells, causing the accumulation of host cell genome mutations and DNA breakage, which can eventually lead to malignant transformation of cells and tumor formation (14).

Our previous results of Illumina sequencing on the subgingival plaque samples from patients with periodontitis and healthy population found that Fusobacterium and Porphyromonas were significantly increased in the periodontitis cohort (15). Therefore, the representative strains of $F$. nucleatum and $P$. gingivalis were selected to carry out an in-depth study on the effect and regulatory mechanism of NLRP3 and DDR of oral epithelial cells under the condition of imbalance of oral ecology. We had successfully constructed the model of periodontitis and identified that the periodontitis-related bacteria ( $P$. gingivalis and $F$. nucleatum) could promote oral tumor growth and proliferation by initiating the overexpressed NLRP3 and activating upstream signal molecules of ATR-CHK1, which was innovative in the analytical elucidation of the possible linkages and regulatory mechanisms of periodontal bacterial infection-periodontitis-OSCC.

\section{MATERIALS AND METHODS}

\section{Bacteria and Culture Conditions}

P. gingivalis ATCC 33277 and F. nucleatum ATCC 25586 were grown in brain heart infusion (BHI; $\mathrm{BD}$, Basingstoke, USA) 
blood agar plate supplemented with hemin $\left(5 \mu \mathrm{g} \mathrm{ml}{ }^{-1}\right)$ and menadione $\left(1 \mu \mathrm{g} \mathrm{ml}^{-1}\right)$ and 5\% defibrinated sheep blood under anaerobic conditions at $37^{\circ} \mathrm{C}$ overnight. Bacteria were harvested in the late exponential growth phase by centrifugation for $10 \mathrm{~min}$ at $4,000 \times \mathrm{g}$ and $4^{\circ} \mathrm{C}$, washed three times with sterile phosphate buffered saline (PBS) before use. According to the relative abundance of previous results of Illumina sequencing, the mixed ratio of the $P$. gingivalis and $F$. nucleatum in periodontitis group $(\mathrm{P}+)$ was $1: 1$. A mixture of $10^{9}$ colonyforming unit (CFU) of bacteria was used in animal experiments.

\section{Culture of Cells}

HSC-3 (human oral squamous carcinoma cell line) and SCC-7 (murine squamous cell carcinoma cell line) were kindly provided by Prof. Qianming Chen from State Key Laboratory of Oral Diseases, West China Hospital of Stomatology, Sichuan University. Cells were grown in Dulbecco's modified Eagle's medium (DMEM; HyClone, Logan, UT, USA) supplemented with $10 \%$ fetal bovine serum (FBS; Gibco, Grand Island, NY, USA) at $37^{\circ} \mathrm{C}$ in a humidified incubator with $5 \% \mathrm{CO}_{2}$. HSC-3 cells were used at $\sim 75 \%$ confluence. Here, $1 \times 10^{8} / \mathrm{ml} \mathrm{SCC-7}$ cells $\left(5 \times 10^{6}\right.$ SCC-7 cells in $50 \mu \mathrm{l}$ DMEM $)$ were constructed for transplanting tumors in mice.

\section{Cell Treatment}

The mixture of $P$. gingivalis and F. nucleatum was resuspended in an appropriated volume of cell culture medium to achieve the desired bacteria-cell ratio at a multiplicity of infection (MOI) of 200 for the indicated time. Although MOI 100 for infection was commonly used, we increased to MOI 200 due to short-term effects of bacteria (16). For Western blot assay, after infection for $8 \mathrm{~h}$, the cells were washed three times and incubated in fresh DMEM supplemented with metronidazole $(200 \mu \mathrm{g} / \mathrm{ml})$ and gentamicin $(300 \mu \mathrm{g} / \mathrm{ml})$ for $12 \mathrm{~h}$. Then, cells were incubated in fresh DMEM until 24 and $48 \mathrm{~h}$ post-infection.

\section{Cell Proliferation Assay}

The effects of bacteria on the viability and proliferation of HSC-3 cells were determined using a Cell Counting Kit-8 (CCK-8; Dojindo, Kumamoto, Japan). Briefly, HSC-3 cells were plated in 96-well plates at $2 \times 10^{3}$ cells per well in the growth medium. Then, $10 \mu \mathrm{l}$ of CCK-8 $(5 \mathrm{mg} / \mathrm{ml})$ was added to each well after bacterial infection at 4,6,12, and $24 \mathrm{~h}$. The cells were incubated for $1 \mathrm{~h}$, and $\mathrm{OD}_{450}$ was measured using a Varioskan Flash microplate reader (Thermo Fisher Scientific). Finally, the $\mathrm{OD}_{450}$ values were converted to cell viability by utilizing standard curves. Each experiment was performed in quadruplicate and repeated at least twice.

\section{Cell Cycle Analysis}

The mixture of $P$. gingivalis and F. nucleatum was resuspended in an appropriated volume of DMEM to achieve the desired HSC-3 bacteria-cell ratio at a MOI of 200 for $8 \mathrm{~h}$. Infected or control HSC- 3 cells were trypsinized, washed with cold PBS, and then fixed in $70 \%$ ethanol at $4^{\circ} \mathrm{C}$ overnight. The cells were then incubated with $\mathrm{RNase} \mathrm{A}$ at $37^{\circ} \mathrm{C}$ for $30 \mathrm{~min}$ and stained with cell cycle detection kit (KeyGEN, Jiangsu, China). Cell cycle was assayed using a flow cytometer (Beckman Coulter, Brea, CA, USA).

\section{Apoptosis Analysis}

For annexin V staining, cells were harvested and stained with an annexin V-fluorescein isothiocyanate (FITC) apoptosis detection kit (KeyGEN, Jiangsu, China) according to the manufacturer's protocol, and flow cytometric analysis (Beckman Coulter) was performed.

\section{Animal Model}

Eight-week-old Balb/c male mice were obtained from where they were group-housed (four mice per cage) in a specific pathogenfree controlled environment. After 1 week, all mice were randomized into two groups: one group was colonized by $P$. gingivalis and $F$. nucleatum $(\mathrm{P}+)$ and another served as control. Mice were treated with antibiotic ( $1 \mathrm{~g} / \mathrm{L}$ ampicillin, $1 \mathrm{~g} / \mathrm{L}$ metronidazole, $1 \mathrm{~g} / \mathrm{L}$ neomycin, $0.5 \mathrm{~g} / \mathrm{L}$ vancomycin) by the oral route in a volume of $25 \mu \mathrm{l}$ for 3 days (17). Antibiotic treatment was stopped for 1 day. For $\mathrm{P}+$ group, $200 \mu \mathrm{l}$ of a mix of bacteria in $2 \%$ carboxymethyl cellulose (CMC) was applied at the surface of the mandibular molar teeth, four times a week, for 1 month. The control group was treated with vehicle (CMC) alone. Then, $5 \times 10^{6}$ SCC-7 cells in $50 \mu$ DEME without FBS were injected into the submucosa of the right cheek after 3 weeks of bacterial colonization. After the tumor inoculation, the longest and shortest diameter of the mass was measured in three directions, and primary tumor growth or formation was evaluated for 3 weeks. All mice were sacrificed on 15 weeks, and their tumors were harvested and weighed. These tumor tissues were processed for Western blot, histological examination, immunostaining, and realtime PCR (including spleen). Mandibular bone was fixed in 10\% formalin for micro-CT test. Animal experiments were approved by the ethics committee of West China Hospital of Stomatology, Sichuan University (WCHSIRB-D-2020-394).

\section{MicroCT Analysis}

Mandible was dissected after euthanasia and scanned with a micro-computed tomography ( $\mu$ CT50, SCANCO) at the voxel resolution of $10 \mu \mathrm{m}$. The amount of alveolar bone was evaluated as previously described by using ImageJ. Mesial and distal bone losses were quantified by measuring the distance between the alveolar bone crest and cement-enamel junction with sagittal images selected in the middle of the tooth. A minimum of four mandibular samples from different mice were examined per group with the analysis performed three times.

\section{Western Blotting}

The proteins of tumor tissues were isolated from snap-frozen tissue samples. Samples for Western blotting were tested by the Total Protein Extraction Kit (SAB, USA) following the manufacturer's instructions. One volume of $4 \times$ sodium dodecyl sulfate (SDS) sample buffer was added, and samples were boiled prior to separation of proteins on $10 \%$ SDS-polyacrylamide gel electrophoresis (PAGE). After transfer of proteins, the polyvinylidene fluoride (PVDF) membranes were blocked in 5\% non-fat dry milk in Tris-buffered saline (TBS) containing $0.05 \%$ 
Tween-20. The antibodies were bought from Cell Signaling Technology and used at the following dilution: $\gamma$-H2AX $(1: 1,000)$, ATR (1:1,000), p-ATR (1:1,000), CHK1 (1:1,000), p-CHK1 (1:1,000), RAD51 (1:1,000). Replication protein 32 (RPA32; 1:500) came from Santa Cruz Biotechnology, and the internal control, $\alpha$-tubulin $(1: 6,000)$, came from Proteintech.

\section{Tumor RNA Isolation and Quantitative Real-Time PCR}

Analysis of gene expression was performed by qRT-PCR. Total RNA was isolated from snap-frozen tissues using TRIzol (Invitrogen), according to the manufacturer's instructions, quantified and evaluated by spectrophotometry. Reverse transcription of RNA into cDNA was performed with the PrimeScript RT Reagent Kit with gDNA Eraser (RR047A; Takara Bio). Real-time polymerase chain reaction was performed with the StepOnePlus Real-time PCR System (Applied Biosystems). The expression levels of IL-6, tumor necrosis factor (TNF)- $\alpha$, nuclear factor (NF)- $\kappa B$, NLRP3, apoptosis-associated speck-like protein containing a CARD (ASC), caspase-1, IL-1 $\beta$, and IL-18 were measured with the glyceraldehyde 3-phosphate dehydrogenase (GAPDH) gene as internal control. All primers in the assay were designed by Primer-BLAST online (National Center for Biotechnology Information, https://www.ncbi.nlm.nih.gov/tools/primer-blast/), and its PCR amplification efficiency reached $90 \%-110 \%$. The PCRs contained $1 \mu \mathrm{mol} / \mathrm{L}$ for each primer pair and $1 \mu \mathrm{l} \mathrm{cDNA}$ sample in a $25-\mu \mathrm{l}$ volume. The PCR program is composed of a $5-\mathrm{s}$ preincubation at $95^{\circ} \mathrm{C}$. Amplification was achieved with 39 cycles of 5 -s denaturation at $95^{\circ} \mathrm{C}, 30$-s annealing at $60^{\circ} \mathrm{C}$, and 5-s extension at $72^{\circ} \mathrm{C}$. All experiments were performed in triplicate. Relative expression was calculated using a $2^{-\triangle \triangle C T}$ method by normalizing with GAPDH as the internal control. The forward/reverse primer sequences were listed in Supplementary Table S1.

\section{Histochemistry, Immunohistochemistry, and Immunofluorescence}

From tumor and spleen tissues after paraffin-embedding, serial sections of $4-\mu \mathrm{m}$ thick were made and stained with hematoxylineosin (H\&E) and immunohistochemistry (IHC). The following antibodies were used: Ki67, cyclin D1, $\gamma$-H2AX, CD4, CD8 (all from Cell Signaling Technology), and CD206 (Alexa Fluor 488, Servicebio, China). After the slides were deparaffinized and rehydrated, antibodies were applied according to the manufacturer's protocol.

\section{Statistical Analysis}

SPSS software (version 19.0; IBM Corporation, Armonk, NY, USA) and GraphPad Prism software (version 6; GraphPad Software, San Diego, CA, USA) were used for statistical analysis. Normal data distributions were analyzed by the Kolmogorov-Smirnov test. If the data are not normally distributed, data were analyzed by nonparametric tests. The normally distributed data were presented as the mean $\pm \mathrm{SD}$, and one-way analysis of variance was used to compare the means. Student's t-test was used for pairwise comparisons between groups. Chi-square test was used to analyze clinical samples, and $\mathrm{p}<0.05$ was considered statistically significant.

\section{RESULTS}

\section{Effect of Coinfection of Periodontitis- Associated Bacteria on Biological Behavior of HSC-3 Cells}

As shown in Figure 1A, compared with the control group, the cell proliferation ability of the $\mathrm{P}+$ group significantly increased from $4 \mathrm{~h}$ and was about 1.4 times that of the control group between 6 and $12 \mathrm{~h}(\mathrm{p}<0.05)$. In addition, the cell proliferation of $\mathrm{P}+$ group decreased slightly at $24 \mathrm{~h}$. Periodontitis-associated bacteria stimulated HSC-3 cells with MOI $=200$ for $8 \mathrm{~h}$. Then, the cells were collected to test the cell cycle and evaluate the percentage of G1, S, and G2/M phase cell populations. As shown in Figure 1B, compared with the control group, a significant accumulation of the percentage of $\mathrm{S}$ phase cells in the $\mathrm{P}+$ group was observed (from $11.9 \%$ to $31.15 \%$ ). However, the G1 cells were obviously reduced (from $64.65 \%$ to $47.19 \%$ ). Moreover, the apoptosis rate of $\mathrm{P}+$ was $0.75 \%$, which was significantly lower than $3.32 \%$ of the rate of control cells (Figure 1C).

\section{Effect of Periodontitis-Associated Bacteria on Alveolar Bone Resorption and Tumor Histology in Tumor-Bearing Mice}

According to the procedure shown in Figure 2A, animal models with an in situ OSCC and periodontitis-associated bacterial treatment were constructed. The results of micro-CT (Figure 2B) showed that the alveolar bone resorption of mice in the $\mathrm{P}+$ group $(75.3 \pm 4.0 \mu \mathrm{m})$ increased by about $53 \%$ compared with that of the control group $(48.8 \pm 1.3 \mu \mathrm{m})$ (Figure 2C). Furthermore, statistical significance was detected in the number of trabecular bone $(\mathrm{Tb} . \mathrm{N})(1 / \mathrm{mm})$ decrease (Figure 2D) $(\mathrm{p}<0.05)$. At the second week after tumor cells were inoculated, the mice were sacrificed, and the tumor tissues were separated and weighed. The tumor mass $(1.24 \pm 0.15 \mathrm{~g})$ in the $\mathrm{P}+$ group was about $30 \%$ higher than that in the blank control group $(0.95 \pm 0.19 \mathrm{~g})$ (Figures 2E, G). At the same time, the tumor volume was measured by Vernier calipers every week, and we found that the tumor growth rate of the $\mathrm{P}+$ group was higher than that of the control group (Figure 2F).

$\mathrm{H} \& \mathrm{E}$ staining of isolated tumors showed that large nuclei with different shapes, large abnormalities, and active abnormal mitotic phenomena were found in both groups (Figure $\mathbf{2 H}$ ). Compared with the control group, large-scale flaky necrosis was found in the tumor tissue of the $\mathrm{P}+$ group. The unclear cell outline and the fragmented and dissolved nucleus were in the necrotic area. Damaged vascular profile and a lot of cell debris were also found. In the non-necrotic area, abnormal and irregular arrangement of the cells was found, but the morphology of tumor cells was complete and clear.

IHC was utilized to detect the expression of Ki67 related to tumor proliferation. A brownish black nucleus indicates positive Ki67 expression. Consistent with the phenotypic trend of the 


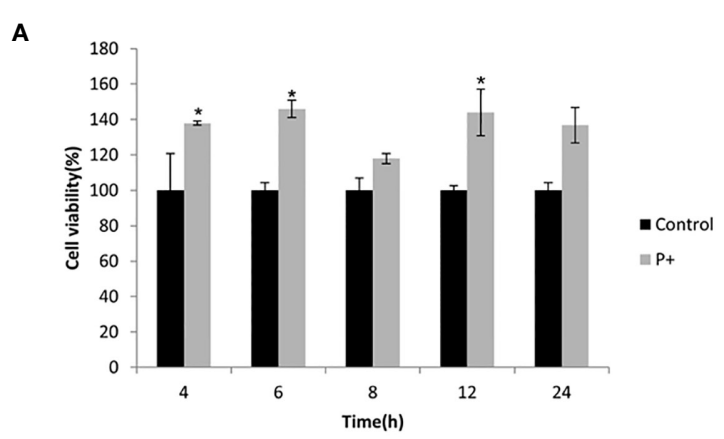

B

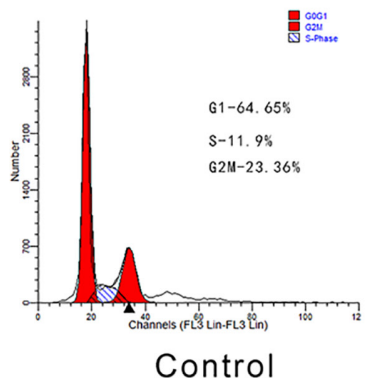

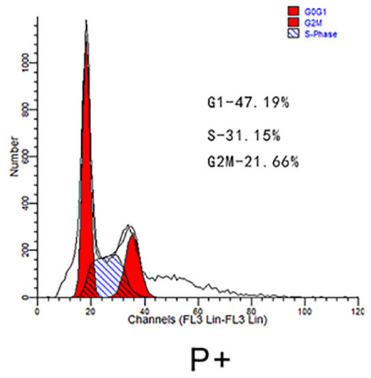

C
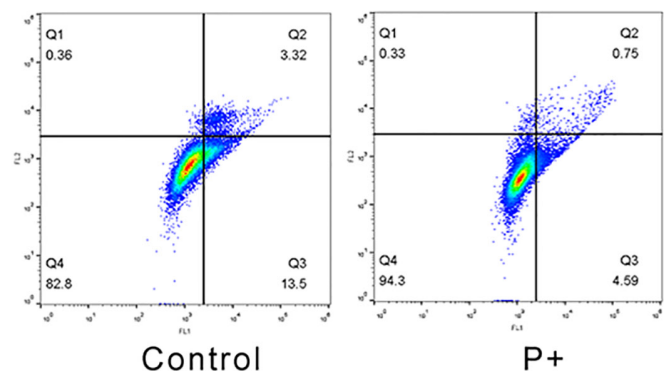

FIGURE 1 | Effect of coinfection of periodontitis-associated bacteria on biological behavior of HSC-3 cells. (A) The cell viability assays of HSC-3. ${ }^{*} p<0.05$. (B) The cell cycle analysis and the specific percentage of G1, S, and G2/M phase cell populations. (C) Apoptosis detection.

tumor tissues, the results of IHC showed that the expression of Ki67 was significantly higher in tumor tissues of the $\mathrm{P}+$ group $(33.19 \% \pm 4.28 \%)$, about 1.5 times that of the control group $(20.38 \% \pm 2.54 \%)(p<0.05)$. In addition, the positive rate of cyclin D1 was significantly higher in tumor tissues of the $\mathrm{P}+$ group $(30.81 \% \pm 6.33 \%)$, approximately 2.5 times that of the control group $(11.69 \% \pm 3.58 \%)(\mathrm{p}<0.05)$ (Figure 3).

\section{Effect of Periodontitis-Associated Bacteria on the Expression of Inflammatory Cytokines in Oral Tumor-Bearing Mice}

To evaluate the expression of inflammatory cytokines in oral cancer, total RNA was isolated from snap-frozen tumor tissues. The qRT-PCR results of the expression of inflammatory cytokines in oral cancer showed that periodontitis-associated bacteria significantly $(\mathrm{p}<0.05)$ upregulated IL-6, TNF- $\alpha$, IL-18, ASC (up to six times), and caspase-1 (up to four times), but it downregulated NF- $\mathrm{KB}, \mathrm{NLRP} 3$, and IL-1 $\beta$ (less than 0.5 times).

\section{Histological and Immune Characteristics of the Spleen}

The volume of spleen tissue in the $\mathrm{P}+$ group increased 2-3 times significantly compared with that in the control group. To determine whether periodontitis-associated bacterial infection altered the histological characteristics of the spleen, $H \& E$ staining was performed. The H\&E staining results showed that compared with control group, diminution of white pulp and congestion of red pulp were found in $\mathrm{P}+$ group (shown by black arrows). Moreover, we detected the change of three types of immune cells in the spleen of the tumor-bearing mice, including CD4+ T cells, CD8+ T cells, and CD206+ T macrophages (Figure 4). The levels of those cells were upregulated 1.5 times by periodontitis-associated bacteria $(\mathrm{p}<0.05)$.

\section{The Periodontitis-Associated Bacteria Induce the ATR-CHK1- Dependent DNA Damage Response in Oral Tumor-Bearing Mice}

The effect of periodontitis-associated bacteria on the expression of $\gamma$-H2AX in oral tumor-bearing mice was detected by immunohistochemistry. As shown in Figure 5A, the number of positive cells in the $\mathrm{P}+$ group increased significantly, which was about three times that of the control group $\left({ }^{\star} \mathrm{p}<0.05\right)$. In agreement, the results of Western blotting in tumor tissues showed that expression levels of $\gamma$-H2AX, p-ATR, RPA32, CHK1, and RAD51 were upregulated, and the phosphorylation level of CHK1 (p-chk1) was downregulated (Figure 5B).

\section{DISCUSSION}

In this study, we intended to explore the effect of periodontitisrelated bacteria on the biological behavior of OSCC, including the expression of inflammasome NLRP3 and the potential mechanism of regulating ATR-CHK1-dependent DNA damage in vivo. It was found that $P$. gingivalis and $F$. nucleatum could promote the proliferation of OSCC and S phase cell cycle arrest, inhibit apoptosis, activate upstream signal molecules of ATR- 
A

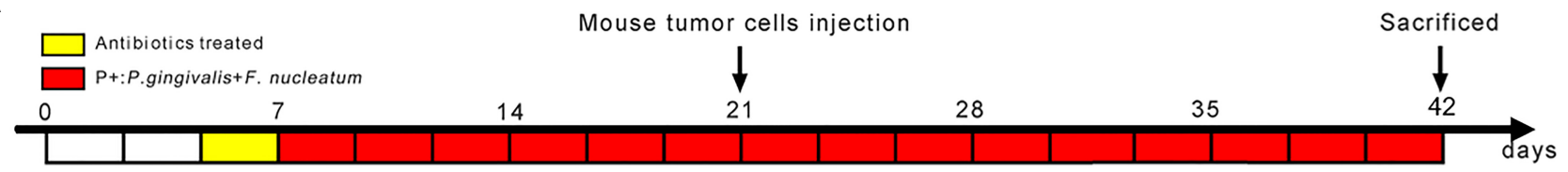

B

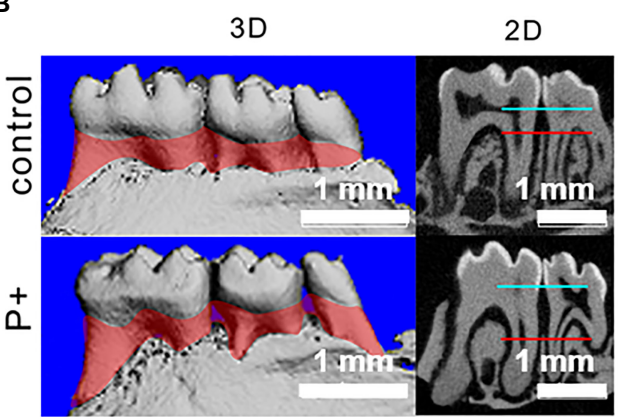

C

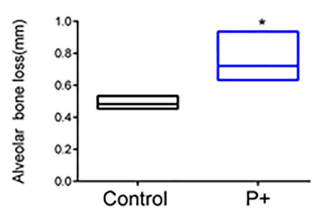

D

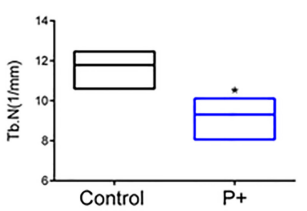

E

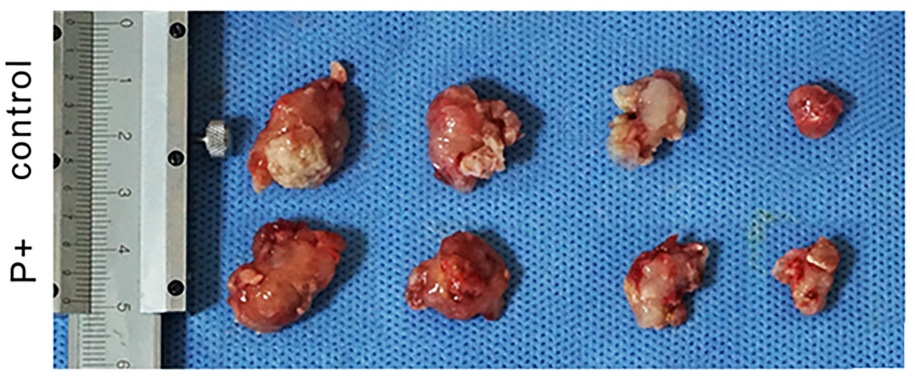

$\mathbf{F}$

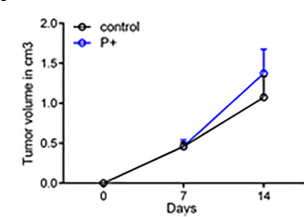

G

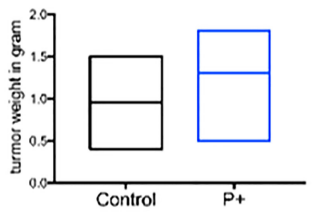

$\mathbf{H}$

HE

Ki67

cyclin D1
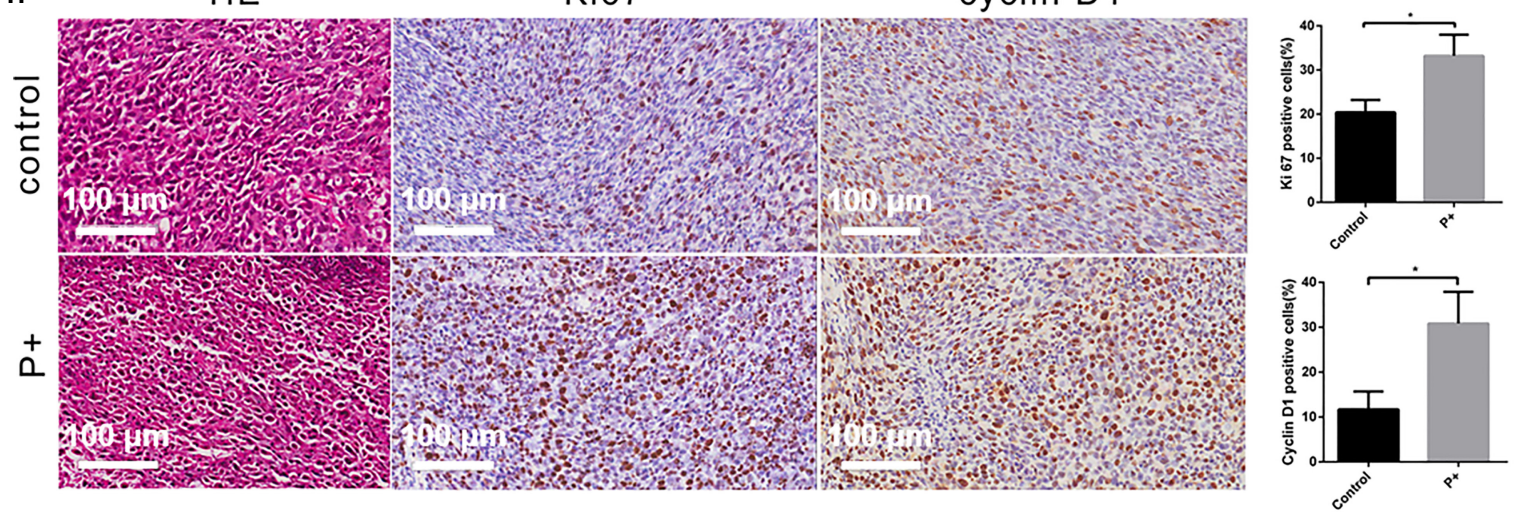

FIGURE 2 | Effect of periodontitis-associated bacteria on alveolar bone resorption and tumor histology in tumor-bearing mice. (A) Flowchart of the experimental design. (B) The microCT analysis. (C) Measurement of the alveolar bone resorption of mice. * $\mathrm{p}<0.05$. (D) Measurement of the number of trabecular bones (Tb. N) $(1 / \mathrm{mm}){ }^{*} p<0.05$. (E) The observation of tumor morphology. (F) Weekly measurement of the tumor volume. (G) Measurement of the tumor mass. (H) H\&E staining and representative immunohistochemistry $(\mathrm{IHC})$ results for Ki67 and cyclin D1, and the percentage of Ki67-positive and cyclin D1-positive cells in the control and P+ groups. ${ }^{*} p<0.05$

CHK1, inhibit the activation of CHK1, and initiate the overexpressed NLRP3.

Chronic periodontitis was a risk factor for oral precancerous lesions and cancer. To date, many studies have suggested a link between periodontitis-related bacteria and oral cancer (17). Recently, microbial dysbiosis has been reported to promote oral tumorigenesis (18). Research focused on the "red complex": $P$. gingivalis, Treponema denticola, and Tannerella forsythia, a prototype polybacterial pathogenic consortium in periodontitis. The representative bacteria of "yellow complex," F. nucleatum, also received more and more attention for the close relationship with the occurrence and development of many tumors. In particular, the combined "red and yellow complex" $(P$. gingivalis and $F$. nucleatum) has been proposed as a potential etiological agent for oral cancer due to its induction of pro-inflammatory cytokines, cell proliferation, cell survival, cell invasion, and cell migration (19-21). Therefore, these authors collected comprehensive data to contribute the association between OSCC and periodontal bacteriome. It was found in this study that $P$. gingivalis and $F$. nucleatum could promote the proliferation of HSC-3 cells in vitro and increase the arrest of S phase cells, similar to previous studies $(22,23)$. The increase of $S$ phase arrest of cell 

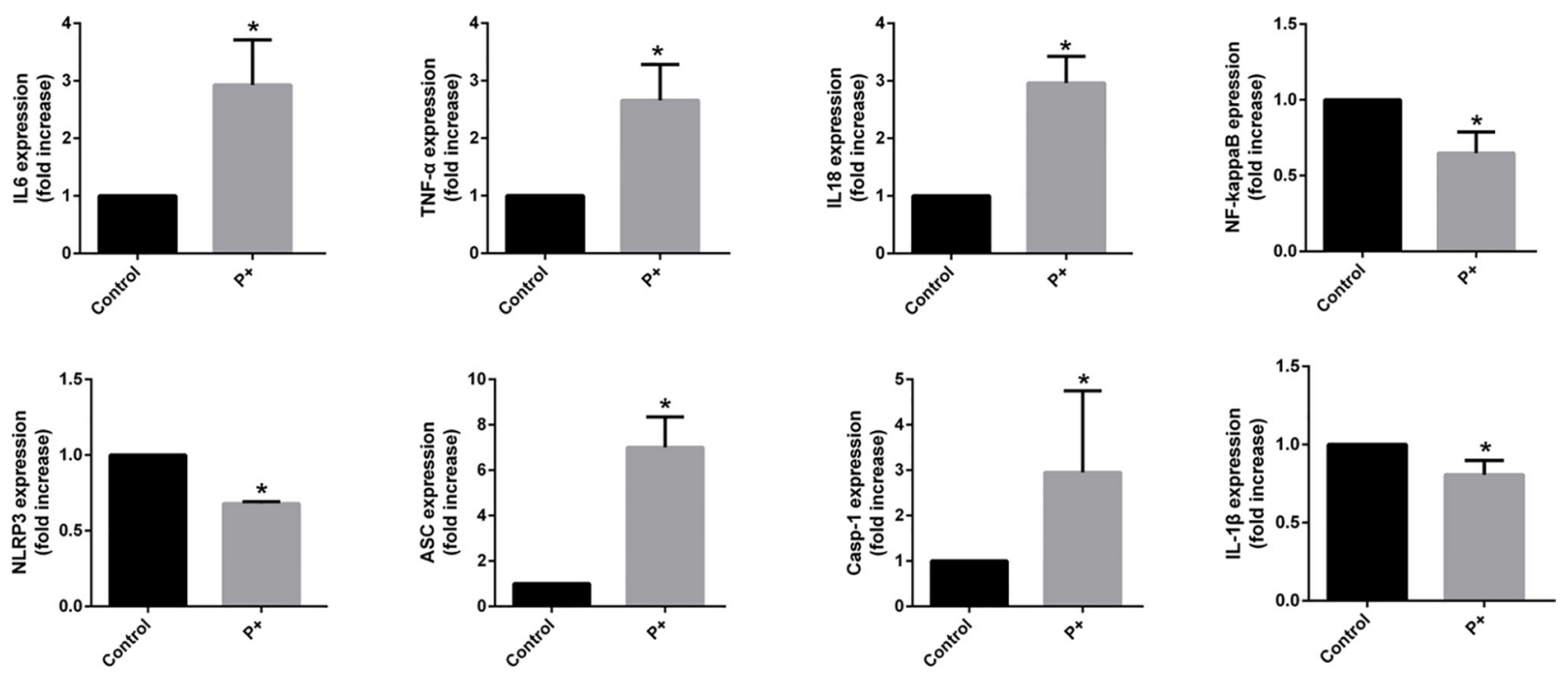

FIGURE 3 | The qRT-PCR results of the expression of inflammatory cytokines in oral tumor-bearing mice, including interleukin (IL)-6, tumor necrosis factor (TNF)- $\alpha$, nuclear factor (NF)- $\mathrm{kB}$, NOD-, LRR- and pyrin domain-containing protein 3 (NLRP3), apoptosis-associated speck-like protein containing a CARD (ASC), caspase-1, $\mathrm{IL}-1 \beta$, and IL-18. ${ }^{*} \mathrm{p}<0.05$.

cycle increased the replication pressure of tumor cells, stimulated the probability of genome mismatch, and promoted the progress of the tumor (24). It was also found in this study that $P$. gingivalis and $F$. nucleatum can promote the expression of cyclin D1, which can promote the cell cycle G1-S transition, leading to the increase of $S$ phase arrest. The similar results were shown in the research on gingival epithelial cells infected by $P$. gingivalis (23). In the primary culture of short-term gingival epithelial cells, $P$. gingivalis can inhibit apoptosis by upregulating antiapoptotic molecule Bcl-2 and downregulating pro-apoptotic Bad (25). The effect of $P$. gingivalis on the apoptosis of oral epithelial cells still needed further research. Some studies have found that when $P$. gingivalis invaded oral cancer cells, the autophagy increased, rather than the apoptosis (26). On the contrary, P. gingivalis and F. nucleatum can inhibit the apoptosis of HSC-3 cells and promote the survival of tumor cells in this study. In our study, the combined "red and yellow complex" ( $P$. gingivalis and F. nucleatum) was given to the cells to elucidate the mechanism between periodontitis and oral tumors tentatively, as the solely bacterial infection has been fully researched. As a consequence, the specific mechanism might be related to the DNA damage and inflammasome NLRP3. However, the dental plaque, the etiological agent for dental caries and periodontal disease, was an archetypical biofilm composed of a complex microbial community. P. gingivalis and $F$. nucleatum are only a part of the complex microbial community. It was tough to elucidate the mechanism between periodontitis and oral tumors comprehensively through a single study of these two bacteria alone or in combination.

DNA damage in host cells caused by genetic toxicity of microorganisms can initiate the overexpressed ATR-CHK1 and the activated DDR to block the progress of cell cycle. Different virulence factors had different regulatory effects on $\operatorname{DDR}(27,28)$.
However, most of these cell cycle captures were transient. With the aggravation of DNA damage and the proliferation of cells, the gene mutations and genomic instability increased, promoting the occurrence and development of tumors (29). In vitro, it was found that $\mathrm{P}+$ group could induce DNA damage in OSCC cells under short-term acute infection, which made $\gamma$-H2AX gradually accumulate with cell proliferation, activate the upstream signal molecule of ATR-CHK1, and increase the phosphorylation level of ATR and RPA2. RPA was recruited to single-stranded DNA fragments in response to replication stress, resulting in recruitment and activation of ATR (30). In addition to the increase in the level of autophosphorylation of ATR, the increase of RPA32 phosphorylation has been used as a reliable marker of ATR activation (31). These results were consistent with the previous studies on the regulation of DNA damage in human trophoblast cells by $P$. gingivalis. In addition, cytolethal distending toxin (CDT) had a similar effect on fibroblasts $(32,33)$. Usually in response to replication stress, $\mathrm{p}$-CHK1 activated the cell cycle checkpoint and promoted DNA damage repair (30). In contrast, it was found in this study that the expression of $\mathrm{CHK} 1$ in $\mathrm{P}+$ group increased, but that of $\mathrm{p}-\mathrm{CHK} 1$ decreased. Due to the inhibition of CHK1 phosphorylation, the interruption of DDR signal transduction, and the inactivation of cell cycle detection points, a large number of damaged DNA substances entered mitosis and genomic instability increased, promoting the occurrence of cancer. Our results were similar to the results of a recent study that Epstein-Barr (EB) virus promoted the deletion of claspin through signal transducer and activator of transcription (STAT)3, which interrupted ATR-Chk1 signal transduction and promoted tumorigenesis (34). However, whether there were other proteins involved in the inhibition of CHK1 phosphorylation by $\mathrm{P}+$ group needs to be further studied. 

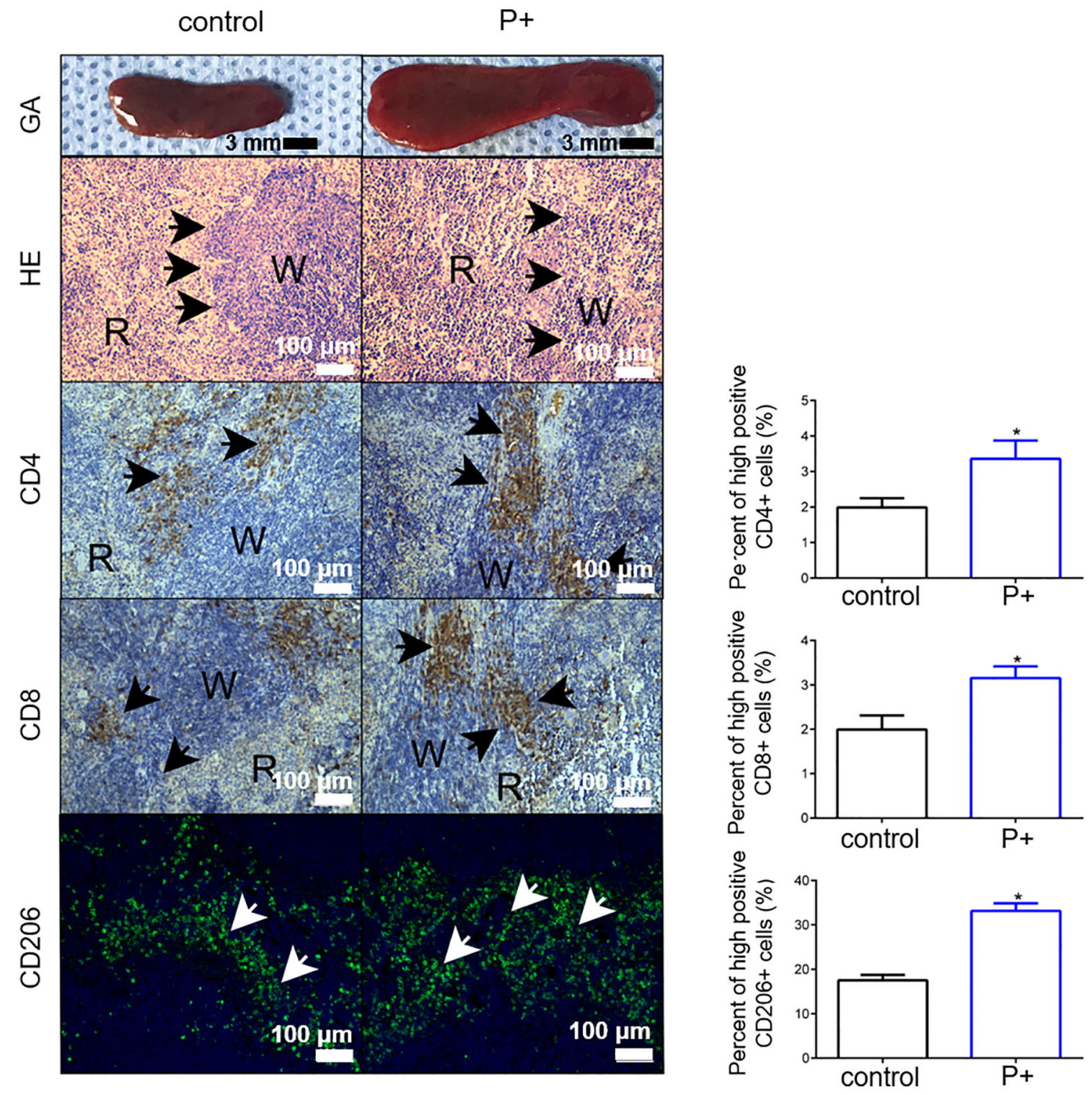

FIGURE 4 | The measurement of the volume of spleen tissue and H\&E staining were performed to observe histological characteristics. The changes of CD4+ T cells, CD8+ T cells, and CD206+ T cells were detected for immune characteristics of the spleen. ${ }^{*} \mathrm{p}<0.05$.

The protein expression was mainly affected by transcriptional translation and the balance of protein stability and degradation (35). It was found that the total protein of ATR was downregulated and the total protein of CHK1 was upregulated, but upregulated at the level of mRNA, indicating that $\mathrm{P}+$ group promoted the degradation of ATR protein. However, CHK1 promoted the transcriptional level to achieve the effect of upregulation. The high expression of CHK1 can also promote the arrest of S-G2M phase of cell cycle (36). The results of in vivo experiments were similar. The similar results were found in the colon cancer cells treated with the CDT. The CDT increased the number of cells with chromosome aberration and decreased their response to DNA damage, resulting in a decrease in their ability to produce $\gamma-\mathrm{H} 2 \mathrm{AX}$ (37). In clinical studies, it was also found that the expression of $\gamma-\mathrm{H} 2 \mathrm{AX}$ was upregulated in gastric precancerous lesions. However, the expression in gastric cancer tissue samples was significantly lower than that in precancerous lesions (38). As a consequence, it was speculated that the downregulation of $\gamma-\mathrm{H} 2 \mathrm{AX}$ in $\mathrm{P}+$ group in vivo may be due to the long-term chronic damage of periodontal pathogens, resulting in the downregulation of tumor cells' response to DNA damage. In addition, the inhibition of CHK1 phosphorylation level in $\mathrm{P}+$ group was more obvious, indicating that chronic stimulation could enhance the inhibitory effect.

Inflammasomes can form a polyprotein complex by combining apoptotic spot-like protein (ASC) and caspase-1 precursor (procaspase-1) with receptor NLRP3 as scaffold. It is 


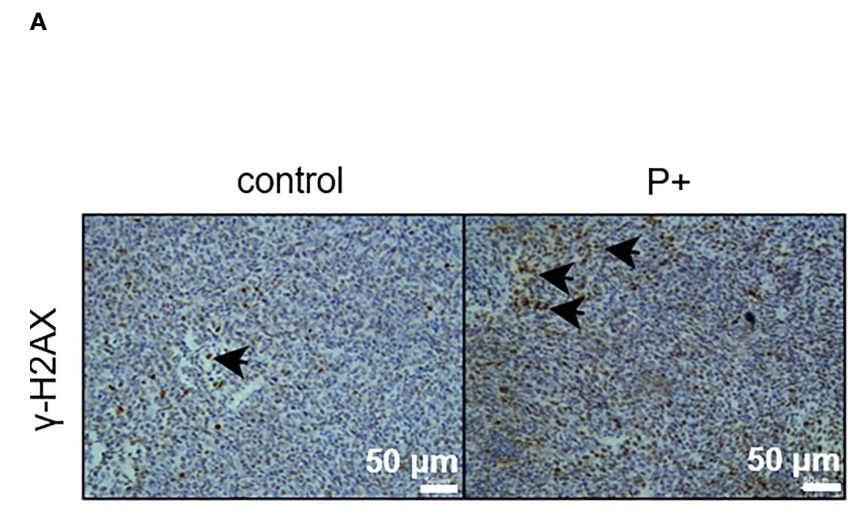

B

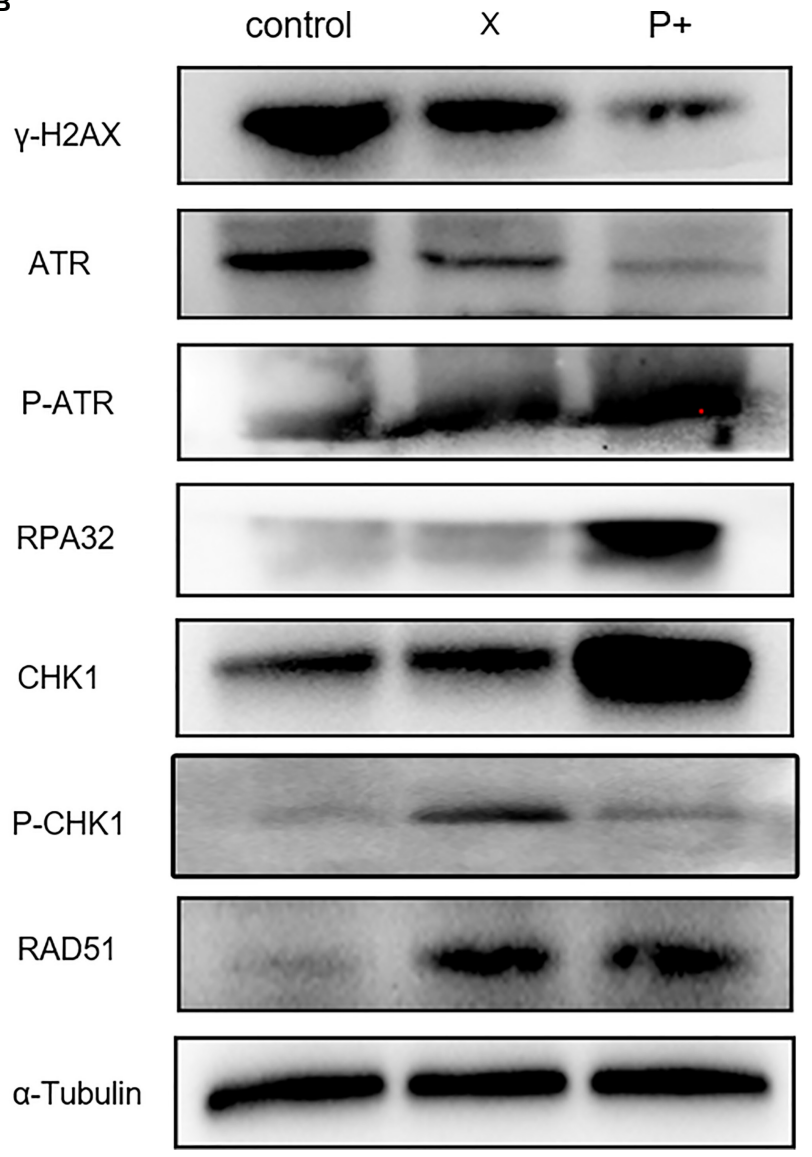

FIGURE 5 | The periodontitis-associated bacteria induce the ATR-CHK1-dependent DNA damage response in oral tumor-bearing mice. (A) The expression of $\gamma$ $\mathrm{H} 2 \mathrm{AX}$ in oral tumor-bearing mice was detected by immunohistochemistry. ${ }^{*} \mathrm{p}<0.05$. (B) The expression levels of $\gamma$-H2AX, ATR, p-ATR, RPA32, CHK1, p-CHK1, RAD51, and $\alpha$-Tubulin in tumor tissues were performed in Western blotting.

the platform of caspase- 1 activation. In addition, it can also be activated by NF- $\kappa \mathrm{B}$, which controls the maturation and secretion of IL-1 $\beta$ and IL-18 and initiates the inflammatory response (39). Recent research showed that NLRP3 was overexpressed in tumor tissues from head and neck squamous cell carcinoma (HNSCC), and its activity levels also correlated with tumor size, lymph node metastatic status, and IL- $1 \beta$ expression, which played a protumorigenic role and enhanced the aggressiveness of HNSCC $(40,41)$. Periodontal pathogens might contribute to HNSCC pathogenesis by increasing the IL-1 $\beta$ response due to inflammasome dysregulation. $P$. gingivalis and F. nucleatum increased IL-1 $\beta$ by upregulating inflammasome AIM2 and downregulating POP1, and $P g$ alone promoted IL-1 $\beta$ by upregulating NLRP3 (20). Inflammasome NLRP3 played an important role in the inflammatory response of gingival epithelial cells (42). In addition, the expressions of NLRP3, IL$1 \beta$, and IL-18 in gingival tissues of patients with gingivitis, invasive periodontitis, and chronic periodontitis were significantly increased (43). Moreover, periodontal pathogens could regulate the expression of NLRP3 inflammasome in gingival fibroblasts (44). As an important regulator of inflammation and cell death, inflammasomes not only were related to immune inflammatory diseases but also played an important role in promoting the development of "normal tissues to chronic inflammation to malignant tumors" $(45,46) . P$. gingivalis could initiate activation of the ATP-P2X7 pathway by regulating NLRP3 that promoted the antiapoptotic enzyme NDK secretion and secreted various virulence factors, inducing the occurrence of OSCC. NLRP3 inflammasome activation had been shown to activate cancer stem cells (CSCs) leading to selfrenewal and acceleration of HNSCC progression $(4,47)$. In addition, periodontitis-related bacteria could also promote the proliferation and invasion of tumor induced by chemical drugs in mice (48). Inflammasomes played a significant contrastive role in the interaction between malignant tumor cells and their microenvironment. In our study, the expression of inflammatory cytokines in OSCC showed that periodontitisassociated bacteria significantly $(\mathrm{p}<0.05)$ upregulated IL-6, TNF- $\alpha$, IL-18, ASC (up to six times), and caspase-1 (up to four times) but downregulated NF- $\mathrm{BB}, \mathrm{NLRP} 3$, and IL-1 $\beta$ (less 
than 0.5 times). Considering the heterogeneity of tumor cells, the expression of NLRP3 inflammasome in the P+tumor tissues was mainly activated. The caspase- 1 activation can cause inflammatory response and carcinogenesis in inflammatory cells. As for the inconsistent expression of cytokines, we were more concerned about the heterogeneity of tumor cells, which included a variety of cells, and the cell-to-cell difference in the expression of inflammasomes or other inflammatory cytokines existed. In the later stage, the cytokine chip or single-cell sequencing of tumor tissue could be a potential solution. Furthermore, elevated NLRP3 expression is associated with chemoresistance in the treatment of HNSCC (49). The inhibition of the NLRP3 inflammasome pathway was suggested to be a promising approach for decreasing tumor cell invasion and survival.

In addition, there was a close connection between the NLRP3 inflammasome activation and reactive oxygen species (ROS) (50). On the one hand, ROS was shown to be a critical mechanism triggering NLRP3 inflammasome formation and activation in response to many exogenous stimuli as well as damage-associated molecular patterns (DAMPs). The inhibition of reduced nicotinamide adenine dinucleotide phosphate (NADPH) oxidase-derived ROS prevented ATP-induced caspase- 1 activation and IL- $1 \beta$ production in alveolar macrophages. In particular, $P$. gingivalis-induced ROS production has been shown to activate the NLRP3 inflammasome in macrophages, leading to an increased production of atherogenic cytokines such as IL-1 $\beta$, IL-18, and TNF- $\alpha$ (51). During the F. nucleatum infection, the depletion of NLRX1, a member of the NLR (NOD-like receptor) family, by shRNA attenuated ATP-induced mitochondrial ROS generation and redistribution of the NLRP3 inflammasome adaptor protein, ASC (52). On the other hand, when NLRP3 inflammasome activation was stimulated by hypercholesterolemia, DAMPs, and so on, the local inflammatory response occurred, and there were the recruitment and activation of inflammatory cells such as macrophages and $\mathrm{T}$ cells, producing cytokines and ROS, resulting in chronic sterile inflammation and leading to tissue injury and sclerosis (50). In our follow-up research, we would further pay attention to the potential mechanisms of the occurrence and development of oral tumor under the action of periodontal microorganisms due to ROS, inflammasome, and DNA damage.

Moreover, there were data suggesting that inflammasome polymorphisms were closely related to DDR, influencing the initiation and development of the disease's lesions. The overexpressed NLRP3 could mimic silica-induced DNA damage and mutagenic double-strand breaks that were documented as increased levels of $\gamma-\mathrm{H} 2 \mathrm{AX}, \mathrm{p}-\mathrm{CHK} 2$ in airway epithelial cells and closely related to the occurrence of lung carcinomas (23). Moreover, mutations in AIM2 led to excessive accumulation of DNA damage in neurons as well as an increase in the number of neurons that incorporated into the adult brain (53). Conversely, NLRP3 inflammasome activation could be initiated by DNA damage induced by ultraviolet, reactive oxygen, candidalysin, and so on (54-57). In this study, we found that overexpressed NLRP3 and DNA damage were simultaneously found in the tumor tissues of $\mathrm{P}+$ group, promoting tumor growth and proliferation.

In conclusion, the periodontitis-related bacteria $(P$. gingivalis and $F$. nucleatum) can initiate the overexpressed NLRP3, activate upstream signal molecules of ATR-CHK1, and inhibit the activation of CHK1, promoting tumor growth and proliferation. It is expected to develop a new molecular mechanism between periodontitis-related bacteria and OSCC.

\section{DATA AVAILABILITY STATEMENT}

The raw data supporting the conclusions of this article will be made available by the authors, without undue reservation.

\section{ETHICS STATEMENT}

The animal study was reviewed and approved by the ethics committee of West China Hospital of Stomatology, Sichuan University (WCHSIRB-D-2020-394).

\section{AUTHOR CONTRIBUTIONS}

YY, XS and BT conceived and designed the research studies, analyzed the data, and wrote the manuscript. YY, XS, and MZ performed the experiments. All authors contributed to the article and approved the submitted version.

\section{FUNDING}

This study was supported by the Innovation and Entrepreneurship Training Program for College Students (grant no. C2019105015) and Open Project Fund for Key Laboratory of Guangdong Science and Technology Department (KF2019120101).

\section{ACKNOWLEDGMENTS}

We are grateful to Prof. Qianming Chen for kindly providing the mouse tumor cell lines and to XS for her assistance in our experiment.

\section{SUPPLEMENTARY MATERIAL}

The Supplementary Material for this article can be found online at: https://www.frontiersin.org/articles/10.3389/fonc.2021.722797/ full\#supplementary-material 


\section{REFERENCES}

1. Hayes RB, Ahn J, Fan X, Peters BA, Ma Y, Yang L, et al. Association of Oral Microbiome With Risk for Incident Head and Neck Squamous Cell Cancer. JAMA Oncol (2018) 4(3):358-65. doi: 10.1001/jamaoncol.2017.4777

2. Cramer JD, Burtness B, Le QT, Ferris RL. The Changing Therapeutic Landscape of Head and Neck Cancer. Nat Rev Clin Oncol (2019) 16 (11):669-83. doi: 10.1038/s41571-019-0227-z

3. Atanasova KR, Yilmaz Ö. Looking in the Porphyromonas Gingivalis Cabinet of Curiosities: The Microbium, the Host and Cancer Association. Mol Oral Microbiol (2014) 29:55-66. doi: 10.1111/omi.12047

4. Galvão-Moreira LV, da Cruz MC. Oral Microbiome, Periodontitis and Risk of Head and Neck Cancer. Oral Oncol (2016) 53:17-9. doi: 10.1016/ j.oraloncology.2015.11.013

5. Fitzpatrick SG, Katz J. The Association Between Periodontal Disease and Cancer: A Review of the Literature. J Dentistry (2010) 38(2):83-95. doi: 10.1016/j.jdent.2009.10.007

6. Tezal M, Grossi SG, Genco RJ. Is Periodontitis Associated With Oral Neoplasms? J Periodontol (2005) 76:406-10. doi: 10.1902/jop.2005.76.3.406

7. Pushalkar S, Ji X, Li Y, Estilo C, Yegnanarayana R, Singh B, et al. Comparison of Oral Microbiota in Tumor and Non-Tumor Tissues of Patients With Oral Squamous Cell Carcinoma. BMC Microbiol (2012) 12:144. doi: 10.1186/14712180-12-144

8. Hajishengallis G, Darveau RP, Curtis MA. The Keystone-Pathogen Hypothesis. Nat Rev Microbiol (2012) 10:717-25. doi: 10.1038/nrmicro2873

9. Geng F, Zhang Y, Lu Z, Zhang S, Pan Y. Fusobacterium Nucleatum Caused DNA Damage and Promoted Cell Proliferation by the Ku70/p53 Pathway in Oral Cancer Cells. DNA Cell Biol (2020) 39(1):144-51. doi: 10.1089/ dna.2019.5064

10. Garrett WS. Cancer and the Microbiota. Science (2015) 348(6230):80-6. doi: 10.1126/science.aaa 4972

11. Mah LJ, El-Osta A, Karagiannis TC. gammaH2AX: A Sensitive Molecular Marker of DNA Damage and Repair. Leukemia (2010) 24(4):679-86. doi: 10.1038/leu.2010.6

12. Song N, Li T. Regulation of NLRP3 Inflammasome by Phosphorylation. Front Immunol (2018) 9:2305. doi: 10.3389/fimmu.2018.02305

13. Moossavi M, Parsamanesh N, Bahrami A, Atkin SL, Sahebkar A. Role of the NLRP3 Inflammasome in Cancer. Mol Cancer (2018) 17(1):158. doi: 10.1186/ s12943-018-0900-3

14. Irrazabal T, Thakur BK, Kang M, Malaise Y, Streutker C, Wong EOY, et al. Limiting Oxidative DNA Damage Reduces Microbe-Induced ColitisAssociated Colorectal Cancer. Nat Commun (2020) 11(1):1802. doi: 10.1038/s41467-020-15549-6

15. Li Y, He J, He Z, Zhou Y, Yuan M, Xu X, et al. Phylogenetic and Functional Gene Structure Shifts of the Oral Microbiomes in Periodontitis Patients. ISME $J(2014)$ 8(9):1879-91. doi: 10.1038/ismej.2014.28

16. Grilli DJ, Mansilla ME, Giménez MC, Sohaefer N, Ruiz MS, Terebiznik MR, et al. Pseudobutyrivibrio Xylanivorans Adhesion to Epithelial Cells. Anaerobe (2019) 56:1-7. doi: 10.1016/j.anaerobe.2019.01.001

17. Polak D, Wilensky A, Shapira L, Halabi A, Goldstein D, Weiss EI, et al. Mouse Model of Experimental Periodontitis Induced by Porphyromonas Gingivalis/ Fusobacterium Nucleatum Infection: Bone Loss and Host Response. J Clin Periodontol (2009) 36(5):406-10. doi: 10.1111/j.1600-051X.2009.01393

18. Mukherjee PK, Wang H, Retuerto M, Zhang H, Burkey B, Ghannoum MA, et al. Bacteriome and Mycobiome Associations in Oral Tongue Cancer. Oncotarget (2017) 8(57):97273-89. doi: 10.18632/oncotarget.21921

19. Zhang WL, Wang SS, Wang HF, Tang YJ, Tang YL, Liang XH. Who is Who in Oral Cancer? Exp Cell Res (2019) 384(2):111634. doi: 10.1016/ j.yexcr.2019.111634

20. Aral K, Milward MR, Gupta D, Cooper PR. Effects of Porphyromonas Gingivalis and Fusobacterium Nucleatum on Inflammasomes and Their Regulators in H400 Cells. Mol Oral Microbiol (2020) 35(4):158-67. doi: 10.1111/omi.12302

21. Holt SC, Ebersole JL. Porphyromonas Gingivalis, Treponema Denticola, and Tannerella Forsythia: The "Red Complex", A Prototype Polybacterial Pathogenic Consortium in Periodontitis. Periodontol 2000 (2005) 38:72122. doi: 10.1111/j.1600-0757.2005.00113.x
22. Katz J, Onate MD, Pauley KM, Bhattacharyya I, Cha S. Presence of Porphyromonas Gingivalis in Gingival Squamous Cell Carcinoma. Int J Oral Sci (2011) 3(4):209-15. doi: 10.4248/IJOS11075

23. Binder Gallimidi A, Fischman S, Revach B, Bulvik R, Maliutina A, Rubinstein $\mathrm{AM}$, et al. Periodontal Pathogens Porphyromonas Gingivalis and Fusobacterium Nucleatum Promote Tumor Progression in an Oral-Specific Chemical Carcinogenesis Model. Oncotarget (2015) 6(26):22613-23. doi: 10.18632/oncotarget.4209

24. Zhang B, Miao T, Shen X, Bao L, Zhang C, Yan C, et al. EB Virus-Induced ATR Activation Accelerates Nasopharyngeal Carcinoma Growth via M2Type Macrophages Polarization. Cell Death Dis (2020) 11(9):742.

25. Karanika S, Karantanos T, Li L, Wang J, Park S, Yang G, et al. Targeting DNA Damage Response in Prostate Cancer by Inhibiting Androgen ReceptorCDC6-ATR-Chk1 Signaling. Cell Rep (2017) 18(8):1970-81. doi: 10.1016/ j.celrep.2017.01.072

26. Nakhjiri SF, Park Y, Yilmaz O, Chung WO, Watanabe K, El-Sabaeny A, et al. Inhibition of Epithelial Cell Apoptosis by Porphyromonas Gingivalis. FEMS Microbiol Lett (2001) 200(2):145-9. doi: 10.1111/j.1574-6968.2001.tb10706.x

27. Cho TJ, Wee SW, Woo VH, Choi JI, Kim SJ, Shin HI, et al. Porphyromonas Gingivalis-Induced Autophagy Suppresses Cell Proliferation Through G1 Arrest in Oral Cancer Cells. Arch Oral Biol (2014) 59(4):370-8. doi: 10.1016/j.archoralbio.2014.01.001

28. Blackford AN, Jackson SP. ATM, ATR, and DNA-PK: The Trinity at the Heart of the DNA Damage Response. Mol Cell (2017) 66(6):801-17. doi: 10.1016/j.molcel.2017.05.015

29. Weber AM, Ryan AJ. ATM and ATR as Therapeutic Targets in Cancer. Pharmacol Ther (2015) 149:124-38. doi: 10.1016/j.pharmthera.2014.12.001

30. Gagnaire A, Nadel B, Raoult D, Neefjes J, Gorvel JP. Collateral Damage: Insights Into Bacterial Mechanisms That Predispose Host Cells to Cancer. Nat Rev Microbiol (2017) 15(2):109-28. doi: 10.1038/nrmicro.2016.171

31. Smith J, Tho LM, Xu N, Gillespie DA. The ATM-Chk2 and ATR-Chk1 Pathways in DNA Damage Signaling and Cancer. Adv Cancer Res (2010) 108:73-112. doi: 10.1016/B978-0-12-380888-2.00003-0

32. Anantha RW, Vassin VM, Borowiec JA. Sequential and Synergistic Modification of Human RPA Stimulates Chromosomal DNA Repair. J Biol Chem (2007) 282(49):35910-23. doi: 10.1074/jbc.M704645200

33. Inaba $H$, Kuboniwa $M$, Sugita $H$, Lamont RJ, Amano A. Identification of Signaling Pathways Mediating Cell Cycle Arrest and Apoptosis Induced by Porphyromonas Gingivalis in Human Trophoblasts. Infect Immun (2012) 80 (8):2847-57. doi: 10.1128/IAI.00258-12

34. Fahrer J, Huelsenbeck J, Jaurich H, Dörsam B, Frisan T, Eich M, et al. Cytolethal Distending Toxin (CDT) is a Radiomimetic Agent and Induces Persistent Levels of DNA Double-Strand Breaks in Human Fibroblasts. DNA Repair (Amst) (2014) 18:31-43. doi: 10.1016/j.dnarep.2014.03.002

35. Koganti S, Hui-Yuen J, McAllister S, Gardner B, Grasser F, Palendira U, et al. STAT3 Interrupts ATR-Chk1 Signaling to Allow Oncovirus-Mediated Cell Proliferation. Proc Natl Acad Sci U S A (2014) 111(13):4946-51. doi: 10.1073/ pnas. 1400683111

36. Alonso-de Vega I, Martin Y, Smits VA. USP7 Controls Chk1 Protein Stability by Direct Deubiquitination. Cell Cycle (2014) 13(24):3921-6. doi: 10.4161/ 15384101.2014.973324

37. Delia D, Fontanella E, Ferrario C, Chessa L, Mizutani S. DNA Damage-Induced Cell-Cycle Phase Regulation of P53 and P21wafl in Normal and ATM-Defective Cells. Oncogene (2003) 22(49):7866-9. doi: 10.1038/sj.onc. 1207086

38. Guidi R, Guerra L, Levi L, Stenerlöw B, Fox JG, Josenhans C, et al. Chronic Exposure to the Cytolethal Distending Toxins of Gram-Negative Bacteria Promotes Genomic Instability and Altered DNA Damage Response. Cell Microbiol (2013) 15(1):98-113. doi: 10.1111/cmi.12034

39. Xie C, Xu LY, Yang Z, Cao XM, Li W, Lu NH. Expression of $\gamma \mathrm{H} 2 \mathrm{AX}$ in Various Gastric Pathologies and Its Association With Helicobacter Pylori Infection. Oncol Lett (2014) 7(1):159-63. doi: 10.3892/ol.2013.1693

40. Wang H, Luo Q, Feng X, Zhang R, Li J, Chen F. NLRP3 Promotes Tumor Growth and Metastasis in Human Oral Squamous Cell Carcinoma. BMC Cancer (2018) 18(1):1-10. doi: 10.1186/s12885-018-4403-9

41. Lee CH, Chang JS, Syu SH, Wong TS, Chan JY, Tang YC, et al. IL-1 $\beta$ Promotes Malignant Transformation and Tumor Aggressiveness in Oral Cancer. J Cell Physiol (2015) 230(4):875-84. doi: 10.1002/jcp.24816 
42. Shao BZ, Xu ZQ, Han BZ, Su DF, Liu C. NLRP3 Inflammasome and Its Inhibitors: A Review. Front Pharmacol (2015) 6:262. doi: 10.3389/fphar.2015.00262

43. Yilmaz O, Sater AA, Yao L, Koutouzis T, Pettengill M, Ojcius DM. ATPDependent Activation of an Inflammasome in Primary Gingival Epithelial Cells Infected by Porphyromonas gingivalis. Cell Microbiol (2010) 12(2):18898. doi: 10.1111/j.1462-5822.2009.01390.x

44. Bostanci N, Emingil G, Saygan B, Turkoglu O, Atilla G, Curtis MA, et al. Expression and Regulation of the NALP3 Inflammasome Complex in Periodontal Diseases. Clin Exp Immunol (2009) 157(3):415-22. doi: 10.1111/j.1365-2249.2009.03972.x

45. Bostanci N, Meier A, Guggenheim B, Belibasakis GN. Regulation of NLRP3 and AIM2 Inflammasome Gene Expression Levels in Gingival Fibroblasts by Oral Biofilms. Cell Immunol (2011) 270(1):88-93. doi: 10.1016/ j.cellimm.2011.04.002

46. Nunes T, de Souza HS. Inflammasome in Intestinal Inflammation and Cancer. Mediators Inflamm (2013) 2013:654963. doi: 10.1155/2013/654963

47. Levy M, Thaiss CA, Zeevi D, Dohnalová L, Zilberman-Schapira G, Mahdi JA, et al. Microbiota-Modulated Metabolites Shape the Intestinal Microenvironment by Regulating NLRP6 Inflammasome Signaling. Cell (2015) 163(6):1428-43. doi: 10.1016/j.cell.2015.10.048

48. Atanasova KR, Yilmaz Ö. Prelude to Oral Microbes and Chronic Diseases: Past, Present and Future. Microbes Infect (2015) 17:473-83. doi: 10.1016/ j.micinf.2015.03.007

49. Feng X, Luo Q, Zhang H, Wang H, Chen W, Meng G, et al. The Role of NLRP3 Inflammasome in 5-Fluorouracil Resistance of Oral Squamous Cell Carcinoma. J Exp Clin Cancer Res (2017) 36(1):81. doi: 10.1186/s13046-017-0553-x

50. Yamaguchi Y, Kurita-Ochiai T, Kobayashi R, Suzuki T, Ando T. Activation of the NLRP3 Inflammasome in Porphyromonas gingivalis-Accelerated Atherosclerosis. Pathog Dis (2015) 73(4):ftv011. doi: 10.1093/femspd/ftv011

51. Abais JM, Xia M, Zhang Y, Boini KM, Li PL. Redox Regulation of NLRP3 Inflammasomes: ROS as Trigger or Effector? Antioxid Redox Signal (2015) 22 (13):1111-29. doi: 10.1089/ars.2014.5994

52. Hung SC, Huang PR, Almeida-da-Silva CLC, Atanasova KR, Yilmaz O, Ojcius DM. NLRX1 Modulates Differentially NLRP3 Inflammasome Activation and NF-kb Signaling During Fusobacterium Nucleatum Infection. Microbes Infect (2018) 20(9-10):615-25. doi: 10.1016/j.micinf.2017.09.014
53. Wu R, Högberg J, Adner M, Ramos-Ramírez P, Stenius U, Zheng H. Crystalline Silica Particles Cause Rapid NLRP3-Dependent Mitochondrial Depolarization and DNA Damage in Airway Epithelial Cells. Part Fibre Toxicol (2020) 17(1):39. doi: 10.1186/s12989-020-00370-2

54. Lammert CR, Frost EL, Bellinger CE, Bolte AC, McKee CA, Hurt ME, et al. AIM2 Inflammasome Surveillance of DNA Damage Shapes Neurodevelopment. Nature (2020) 580(7805):647-52. doi: 10.1038/s41586-020-2174-3

55. Hasegawa T, Nakashima M, Suzuki Y. Nuclear DNA Damage-Triggered NLRP3 Inflammasome Activation Promotes UVB-Induced Inflammatory Responses in Human Keratinocytes. Biochem Biophys Res Commun (2016) 477(3):329-35. doi: 10.1016/j.bbrc.2016.06.106

56. Chi W, Hua X, Chen X, Bian F, Yuan X, Zhang L, et al. Mitochondrial DNA Oxidation Induces Imbalanced Activity of NLRP3/NLRP6 Inflammasomes by Activation of Caspase-8 and BRCC36 in Dry Eye. J Autoimmun (2017) 80:6576. doi: 10.1016/j.jaut.2017.02.006

57. Engku Nasrullah Satiman EAF, Ahmad H, Ramzi AB, Abdul Wahab R, Kaderi MA, Wan Harun WHA, et al. The Role of Candida Albicans Candidalysin ECE1 Gene in Oral Carcinogenesis. J Oral Pathol Med (2020) 49(9):835-41. doi: $10.1111 /$ jop. 13014

Conflict of Interest: The authors declare that the research was conducted in the absence of any commercial or financial relationships that could be construed as a potential conflict of interest.

Publisher's Note: All claims expressed in this article are solely those of the authors and do not necessarily represent those of their affiliated organizations, or those of the publisher, the editors and the reviewers. Any product that may be evaluated in this article, or claim that may be made by its manufacturer, is not guaranteed or endorsed by the publisher.

Copyright (c) 2021 Yao, Shen, Zhou and Tang. This is an open-access article distributed under the terms of the Creative Commons Attribution License (CC BY). The use, distribution or reproduction in other forums is permitted, provided the original author(s) and the copyright owner(s) are credited and that the original publication in this journal is cited, in accordance with accepted academic practice. No use, distribution or reproduction is permitted which does not comply with these terms. 